\title{
Gland Branching
}

National Cancer Institute

\section{Source}

National Cancer Institute. Gland Branching. NCI Thesaurus. Code C82993.

An architectural morphologic finding indicating branching of glands as a result of a pathologic process. 